\title{
Analysis of relation between the 3D printer laser beam power and the surface morphology properties in Ti-6Al-4V titanium alloy parts
}

\author{
Jerzy Józwik ${ }^{1} \cdot$ Dawid Ostrowski $^{2} \cdot$ Radosław Milczarczyk $^{3} \cdot$ Grzegorz M. Krolczyk $^{4}$
}

Received: 27 July 2016/Accepted: 18 September 2017 / Published online: 27 March 2018

(c) The Author(s) 2018

\begin{abstract}
Additive technologies are increasingly widespread in the aviation industry, medicine and implantology. It is essential that the parts manufactured for these applications meet the highest requirements not only as far as their strength, but also surface quality. Thus, high importance should be attached to performing analysis of the manufactured part's surface morphology to ensure optimised functionality, and to selecting appropriate post-processes so as to arrive at the required external surface structure. The paper aims to establish the influence of technological parameters (chiefly of the laser power) of the selective laser melting (SLM) process on the morphological properties of the manufactured surfaces. The changes of characteristics of the Sa and Sq parameters in the laser power $P$ function are non-linear. However, for some values of laser power $P(150,175 \mathrm{~W})$, the Sa and Sq parameters are considerably higher than that in case of the remaining laser power values. The change of the laser power has a strong influence on the structure of individual surfaces, as evidenced by the fact that the highest values of the Sa and Sq parameters were achieved at different laser powers (175 W for the top surface and $150 \mathrm{~W}$ for the side surface). The results are shown in graphic form of 2D and 3D morphology profiles and charts. Based on the analysis of parameters describing surface structure properties, optimum values of laser power during SLM process are established. The study also revealed that surface structure analysis should not be focused solely on basic parameters such as average height $(\mathrm{Sa})$ or root-mean-square height $(\mathrm{Sq})$, but also on parameters such as kurtosis (Sku) and skewness (Ssk), which yield important information on surface stereometry. Precisely established surface stereometry allows assessing properties such as wear resistance, corrosion, tribological properties, and the ability to integrate medical implants with live organism tissue.
\end{abstract}

Keywords Additive manufacturing $\cdot$ Surface metrology $\cdot$ Surface morphology $\cdot$ Ti-6Al-4V $\cdot$ Laser power

\section{Introduction}

Dynamic development of additive technologies constantly broadens the range of applications of parts thus produced. The application of the technology goes far beyond building

Technical Editor: Fernando Antonio Forcellini.

Grzegorz M. Krolczyk

g.krolczyk@po.opole.pl

1 Department of Production Engineering, Mechanical Engineering Faculty, Lublin University of Technology, Nadbystrzycka Street 38, 20-618 Lublin, Poland

2 State School of Higher Education, Institute of Technical Sciences and Aviation, Pocztowa Street 54, 22-100 Chełm, Poland prototypes and allows manufacturing of final, fully functional elements [1]. The use of laser beam in additive manufacturing processes enables producing parts from a wide range of materials. Depending on the technology, these may include, inter alia, polymers [2], ceramic [3] and metallic materials, i.e. copper alloys, tool steel [4], stainless steel [5], nickel-based alloys [1-7] and cobalt-based

3 Asseco Business Solutions S.A., Konrada Wallenroda Street 4c, 20-607 Lublin, Poland

4 Department of Manufacturing Engineering and Automation, Faculty of Mechanical Engineering, Opole University of Technology, Mikolajczyka Street 5, 45-271 Opole, Poland 
alloys [8], as well as aluminium [9, 10] and titanium alloys $[11,12]$.

Selective laser sintering (SLS), direct metal laser sintering (DMLS), or selective laser melting (SLM) of metal powders are used especially in the automotive and aviation industry, as well as in areas related to biomedicine and implantology [13-16]; the determining factor here being the ability to build elements with complex internal and external geometries. Ensuring the required quality is an important task in the process of manufacturing parts for the above-mentioned branches. Depending on the application, various surface structures might be required. For instance, medical implants, as opposed to most cases of mechanical parts, usually require porous/rough structure that facilitates osseointegration processes [17]. Unfortunately, despite many advantages, SLM of metal powders is a complex physico-chemical process, where full control over the surface structure is exceptionally difficult to achieve. Nevertheless, these are the morphological properties of the surface that frequently define the performance and the correct cooperation of mechanical parts, or the biocompatibility of implants $[18,19]$. Thus, it is important to optimise the process not only as far as the resulting strength properties, but also as far as surface topography. The quality of surface in elements manufactured using SLM processes may be determined by numerous factors, including the properties of the molten material, e.g. the density and size of powder particles [20]. Technological aspects such as the position of the object built in the workspace, the scanning strategy, and the process parameters also have a decisive impact on the result $[16,18,21,22]$.

In [16], the authors establish the influence of wall inclination angle (stair effect), and the thickness of molten layer on surface roughness. Difference in the roughness of the top and bottom surfaces of Ti-6Al-4V titanium alloy elements is also observed. A mathematical model allowing prediction of the actual roughness for different surface inclination angles is presented in [23]. The model was developed on parts manufactured from steel powder using SLM method and takes into account not only the influence of the stair effect, but also the concentration of particles on the top surface.

The literature also offers solutions for improving the quality of surface in elements created using the SLM method. Based on the results presented in $[22,24]$ it can be concluded that re-melting the last layer deposited can favourably influence the surface structure. Using that method, the average roughness of inclined walls was decreased by as much as $70 \%$ [22].

The morphological properties of elements built from titanium alloy with the SLM technology are also heavily influenced by the technological parameters of the process related to the laser power density and the scanning strategy, which was confirmed in [25, 26]. Another study [22] proves that using large scan spacing distances between consecutive scan lines (scan spacing factor) and applying very low laser power considerably decrease the quality of surface manufactured from metal powder. A wider analysis and proposal of optimisation of the Ti-6Al-4V powder laser melting process is put forward in [27] in which the relation between the technological parameters (laser power, scan speed) was confirmed. The authors distinguished various melting mechanisms within the SLM process that influence the surface structure, established the optimum laser power values and scan speeds, and defined the so-called balling effect that increases surface roughness. This phenomenon is typical for the SLM process and was described in detail in [28, 29]. Also, many authors [31-42] analysed the surface properties during different machining processes, like cutting, water-abrasive process and laser cutting.

\section{Materials and methods}

Selecting optimum values for individual SLM process parameters is fundamental to obtaining desired morphological properties of the surface. From among the technological parameters (energy density, laser power, scanning velocity, hatch distance, layer thickness) described by (1), laser power $(P)$ was selected for the purposes of the paper, and the influence of its level on the stereometric characteristics of the manufactured specimen's surface was established:

$E_{\mathrm{d}}=\frac{P}{v_{\mathrm{sc}} \cdot h \cdot t}$

where $E_{\mathrm{d}}$ is the energy density, $P$ is the laser power, $v_{\mathrm{sc}}$ is the scanning velocity, $h$ is the hatch distance and $t$ is the layer thickness.

The object of the study was dog-bone specimens (Fig. 1). This type of specimen is typically used in tensile testing. The shape and dimensions of the specimens were based on the dimensions of the working space, and the need to carry out a variety of tests (surface topography and strength testing).

The specimens were prepared using the SLM method from the Ti-6Al-4V titanium alloy. The chemical composition of the alloy is shown in Table 1. The material (Ti$6 \mathrm{Al}-4 \mathrm{~V})$ is characterised by high strength, corrosion resistance, low expansion and weak thermal conductivity. Due to its biocompatibility, its main application is for implants, its use in other industries includes aviation, defence, automotive, sports and equipment. 

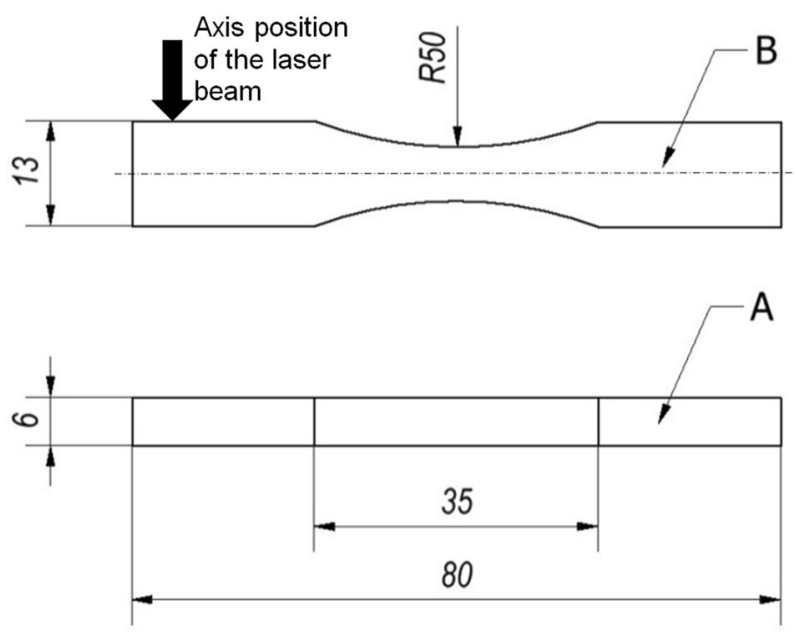

Fig. 1 Geometric parameters of test specimens

Each specimen was formed using a different power of laser beam between 100 and $200 \mathrm{~W}$ (at $25 \mathrm{~W}$ intervals). The location of the laser beam axis is shown schematically in Fig. 1. For the remaining parameters characterising the melting process, the following constant values were set: scanning velocity $v=290 \mathrm{~mm} / \mathrm{s}$, hatch distance $H=0.15 \mathrm{~mm}$ and layer thickness $t=30 \mu \mathrm{m}$. In accordance with (1), the value of laser beam power density $E$ was found. The values of all the parameters used in the experiment are shown in Table 2.

Morphological tests were conducted on the top surface A (perpendicular to the laser beam axis), and the side surface B (parallel to the laser beam axis) (Fig. 1). The Infinite Focus system produced by Alicona enabling stereometric testing and statistical analysis of surface structure parameters was used for the purpose of conducting the test (Fig. 2).

Table 1 Ti-6Al-4V titanium alloy chemical composition

\begin{tabular}{llllllllll}
\hline & $\mathrm{Ti}$ & $\mathrm{Al}$ & $\mathrm{V}$ & $\mathrm{Fe}$ & $\mathrm{O}$ & $\mathrm{C}$ & $\mathrm{H}$ & $\mathrm{N}$ & Other \\
\hline Min. (\%) & - & 5.50 & 3.50 & - & - & - & - & - & - \\
Max. (\%) & 90 & 6.75 & 4.50 & 0.25 & 0.13 & 0.08 & 0.05 & 0.012 & 0.10 each $(0.40$ in total) \\
\hline
\end{tabular}

Table 2 Parameters used in specimen preparation process

\begin{tabular}{llllll}
\hline Specimen & Laser power, $P(\mathrm{~W})$ & Scanning velocity, $v(\mathrm{~mm} / \mathrm{s})$ & Hatch distance, $H(\mathrm{~mm})$ & Layer thickness, $t(\mathrm{~mm})$ & Energy density, $E\left(\mathrm{~J} / \mathrm{mm}^{3}\right)$ \\
\hline 1 & 200 & 290 & 0.15 & 0.03 & 153 \\
2 & 175 & & & & 134 \\
3 & 150 & & & 115 \\
4 & 125 & & & 96 \\
5 & 100 & & & 77 \\
\hline
\end{tabular}

Fig. 2 Focus variation microscope InfiniteFocus ${ }^{\circledR}$ IF G5 used in the experimental investigations

\section{Results and discussion}

The 2D surface morphologies of the top (A) and side (B) surfaces generated for varying laser beam power are shown in Figs. 3 and 4, respectively. The light spots (white, red, and yellow) indicate the peaks of the 3D surface profile, while the dark fields (green, blue and black) are the pits. The size of spots suggests that the profile is 'flattened', which was confirmed by the skewness analysis (Ssk). The smaller the spots of a given colour, the sharper the 3D profile peaks. As it turns out, the side surface B is 
(a) $\mathrm{mm}$ Surface A, $100 \mathrm{~W}$
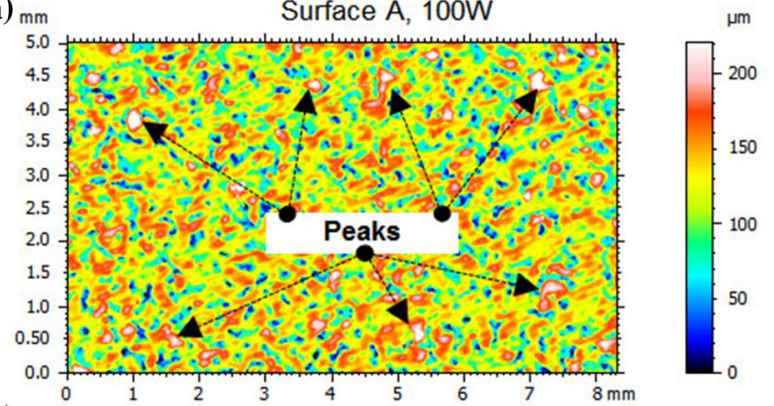

(b)

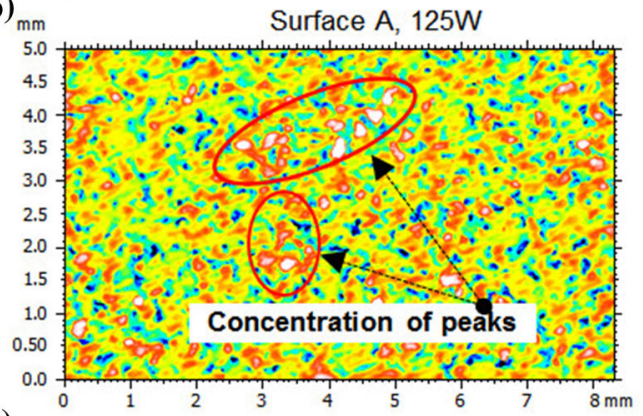

(c)

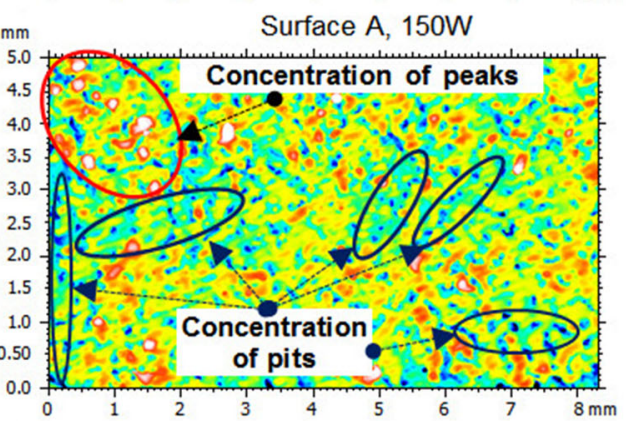

(d)

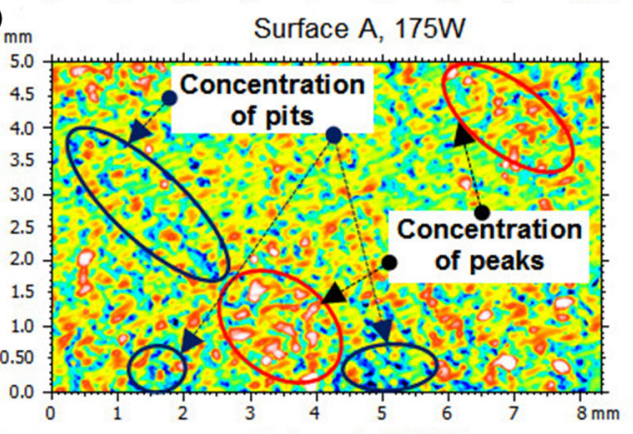

(e) $\mathrm{mm}$

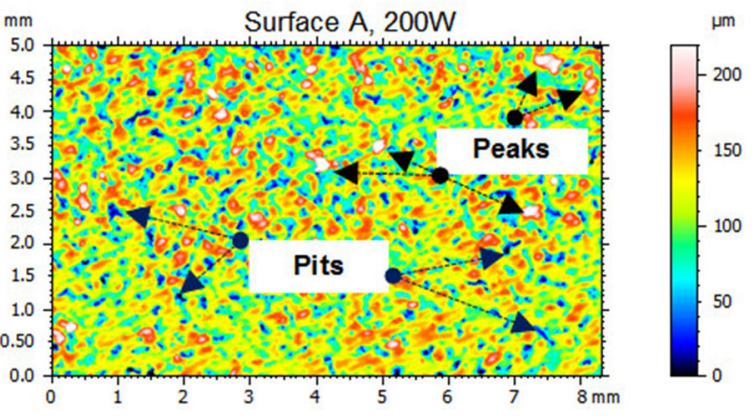

Fig. 3 Comparison of $2 \mathrm{D}$ structures of the top surface (A) of specimens manufactured additively using varying laser beam powers: a $100 \mathrm{~W}$, b $125 \mathrm{~W}$, c $150 \mathrm{~W}$, d $175 \mathrm{~W}$, e $200 \mathrm{~W}$ (a)

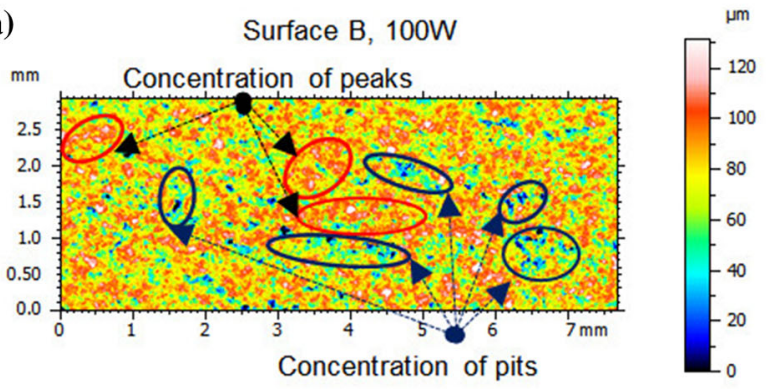

(b)

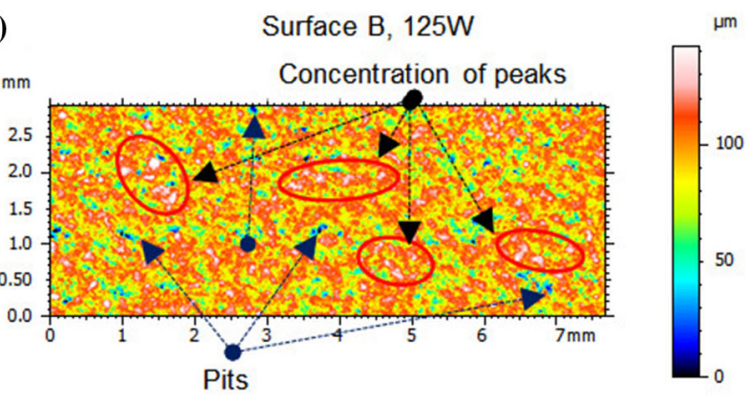

(c)

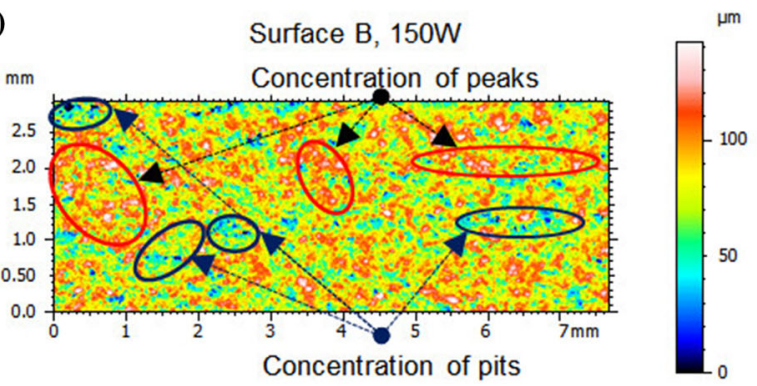

(d)

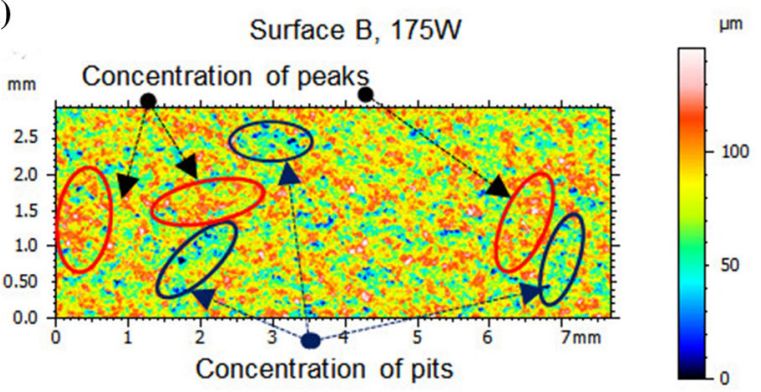

(e)

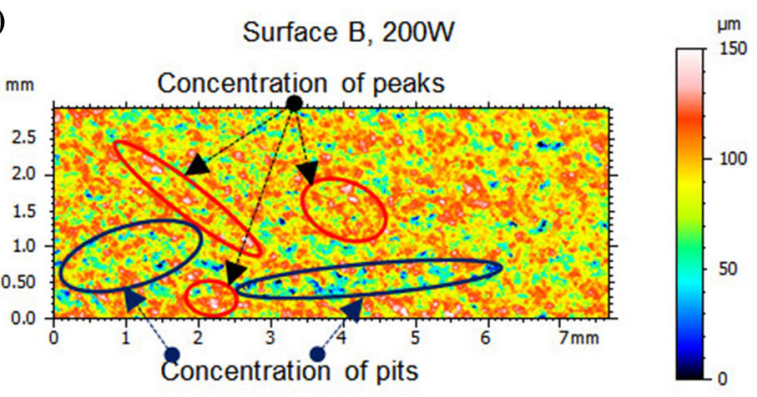

Fig. 4 Comparison of 2D structures of the side surface (B) of specimens manufactured additively using varying laser beam powers: a $100 \mathrm{~W}$, b $125 \mathrm{~W}$, c $150 \mathrm{~W}$, d $175 \mathrm{~W}$, e $200 \mathrm{~W}$ 
(a)

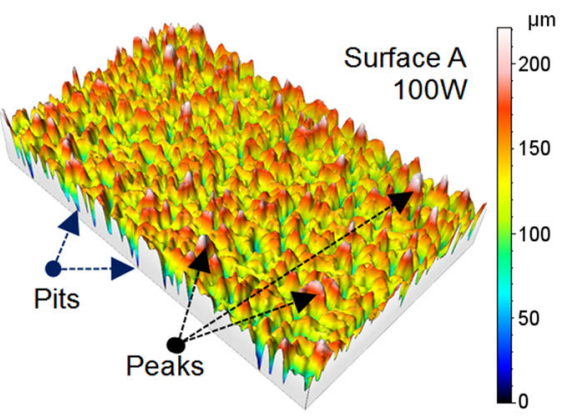

(b)

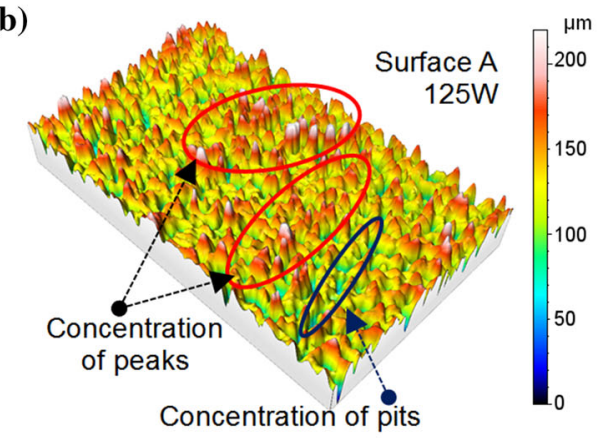

(c)
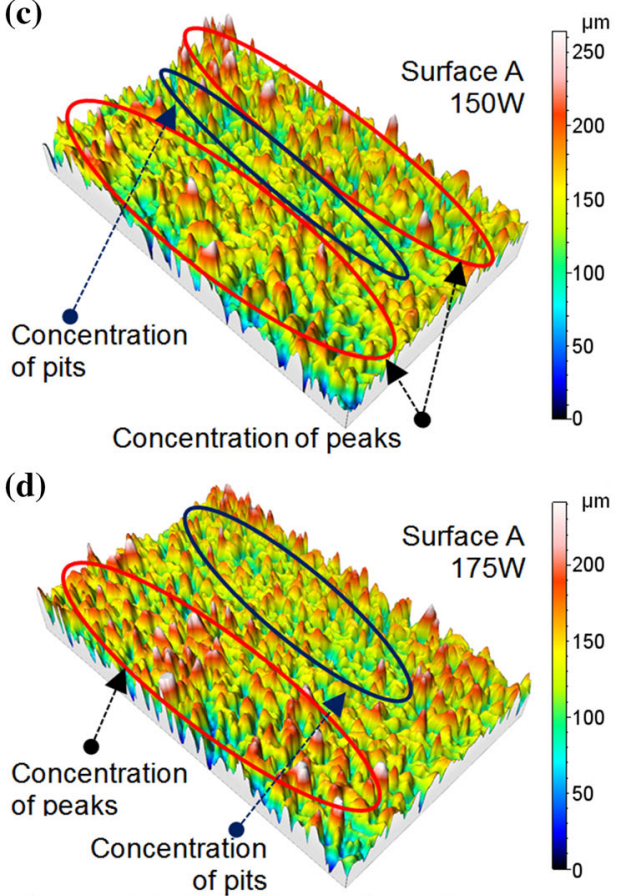

(e)

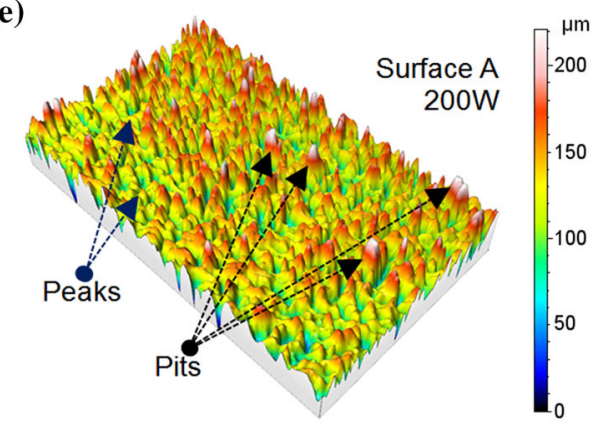

4Fig. 5 Comparison of 3D structures of the top surface (A) of specimens manufactured additively using varying laser beam powers: a $100 \mathrm{~W}$, b $125 \mathrm{~W}$, c $150 \mathrm{~W}$, d $175 \mathrm{~W}$, e $200 \mathrm{~W}$

characterised by tall and sharp peaks, as evidenced by the tightly packed fine spots (Fig. 4), whereas flatter peaks, larger and less densely spotted are characteristics of top surface A (Fig. 3).

The parameters of the geometric structure of top surface (A) were established based on a $5 \mathrm{~mm} \times 8.3 \mathrm{~mm}$ rectangular area, with a $3.5 \mathrm{~mm} \times 7.7 \mathrm{~mm}$ area serving as basis for the side surface (B). The 2D (Figs. 3, 4) and 3D (Figs. 5, 6) surface morphology profiles reveal different distribution of macro- and micro-irregularities, visible to the naked eye. Analysis of surface morphology profiles (3D) reveals that the shape of the irregularities depends on the printer laser beam power $(P)$ and the type of surface tested (top A, side B), whose structure results from the position of the laser beam axis versus the surface molten during the manufacturing process (Fig. 2). The variable density of peaks on the side surface $B$ is clearly visible (Fig. 6) compared to the top surface A (Fig. 5).

Based on the morphological profile's quantitative analysis, characteristics of spatial relationships of roughness parameters in the function of laser beam power were studied. The results of the analysis for surfaces A and B are shown in Fig. 7. Figure 7a, c shows the relationships of the average height $\mathrm{Sa}(P)$ and root-mean-square height $\mathrm{Sq}$ $(P)$ parameters, and Fig. 7b, d shows the relationships of maximum peak height $\mathrm{Sp}(P)$ and maximum valley depth $\mathrm{Sv}(P)$ throughout the entire laser beam power $P$ variation range. Analysing Fig. 7a, it can be observed that the lowest level of roughness (described both by average height Sa and root-mean-square height Sq parameters) was achieved with laser power of $125 \mathrm{~W}$, the values achieved being $\mathrm{Sa} \approx 27.6 \mu \mathrm{m}, \mathrm{Sq} \approx 36 \mu \mathrm{m}$, respectively. The highest roughness levels were found in surfaces manufactured using laser beam power of $175 \mathrm{~W}$. The valid spatial parameters of the surface roughness were the following: $\mathrm{Sa}=31.92 \mu \mathrm{m}$ and $\mathrm{Sq}=40.2 \mu \mathrm{m}$. It should be pointed out that the characteristics of the $\mathrm{Sa}$ and $\mathrm{Sq}$ parameters in the laser power function are non-linear. Due to the wide dispersion around the mean value and the comparatively low number of variables of the laser beam power $P$, they are difficult to linearise. However, it can be stated that, in the initial phase, increasing the laser power results in an inconsiderable decrease of values of spatial parameters describing the geometrical structure of surface, followed by their increase. Once the maximum $\mathrm{Sa}$ and $\mathrm{Sq}$ values were achieved (Fig. 7a) for laser power of $175 \mathrm{~W}$, the trend changed. This is shown by considerably lower values of the $\mathrm{Sa}$ and Sq parameters for laser beam power $P$ of $200 \mathrm{~W}$ 
(a)

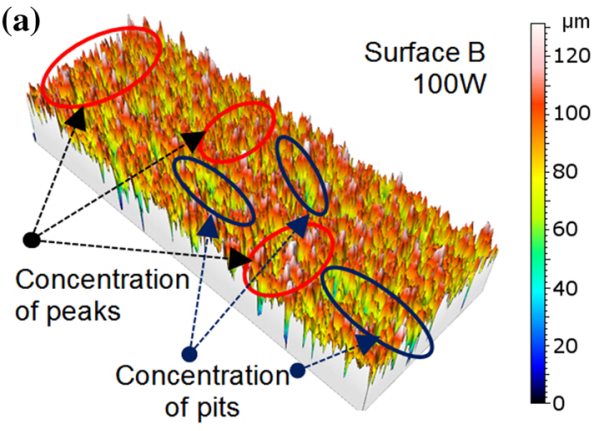

(b)

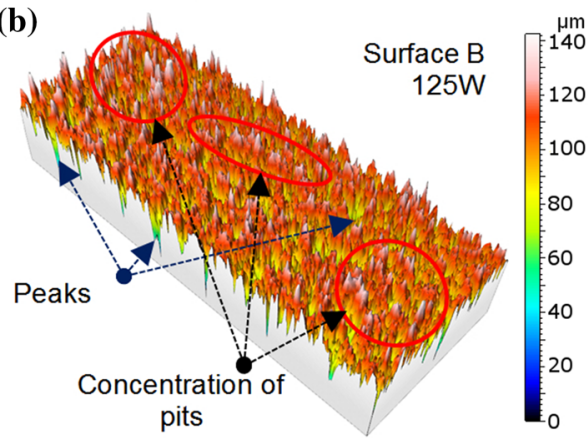

(c)

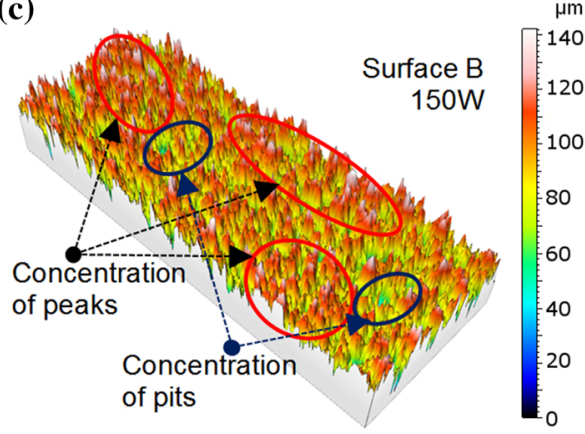

(d)

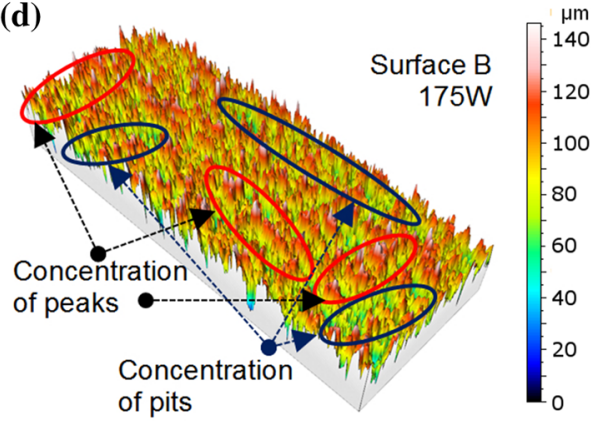

(e)

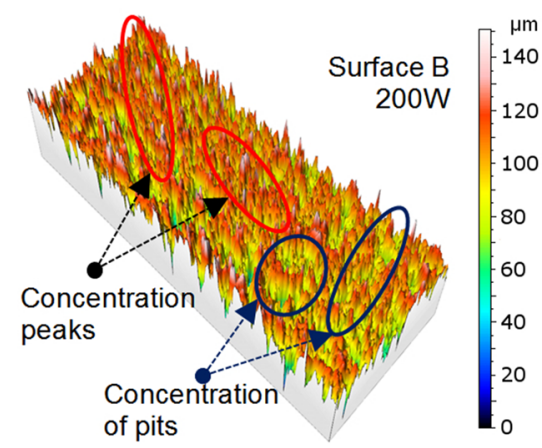

4Fig. 6 Comparison of 3D structures of the side surface (B) of specimens manufactured additively using varying laser beam powers: a $100 \mathrm{~W}$, b $125 \mathrm{~W}$, c $150 \mathrm{~W}$, d $175 \mathrm{~W}$, e $200 \mathrm{~W}$

(lower than for two previous values of laser power $P$ ). The highest value of maximum peak height $(\mathrm{Sp}=135 \mu \mathrm{m})$ was recorded for a specimen manufactured using laser beam with $P=150 \mathrm{~W}$ (Fig. 7b), and the lowest ( $\mathrm{Sp}=97.5 \mu \mathrm{m})$ for a specimen manufactured using laser power $P=100 \mathrm{~W}$. The $\mathrm{Sv}$ values achieved are comparable and remain between 116 and $135 \mu \mathrm{m}$, with the highest value achieved for specimen manufactured using laser beam power of $150 \mathrm{~W}$ (Fig. 7b).

Analogical analysis was carried out for the side surface (B) of the manufactured specimens, characterised by entirely different surface morphology. As in the case of the top surface $\mathrm{A}$, the highest structure regularity is observed in specimens manufactured using laser power $P=125 \mathrm{~W}$. The topographies of the remaining specimens reveal clearly visible areas of hills (in white) and valleys (in dark blue). To establish the parameters of the surface structure, a $3 \times 7.7 \mathrm{~mm}$ rectangle was marked. The values of roughness parameters Sa and Sq (Fig. 7c) are much lower on the side surface (B) compared to the top surface (A), and remain within the following ranges: $\mathrm{Sa}=14.7 / 17.6 \mu \mathrm{m}$ and $\mathrm{Sq}=19.1 / 22.3 \mu \mathrm{m}$ (comp. Fig. $7 \mathrm{a}, \mathrm{c}$ ). The course of change of characteristics is similar, with the highest values of these parameters observed in specimen manufactured using laser power of $175 \mathrm{~W}$, and the lowest in specimen manufactured using laser power of $125 \mathrm{~W}$. The maximum peak height $(\mathrm{Sp}=64.8 \mu \mathrm{m})$ was also found in this specimen. The lowest values of side surface (B) geometrical structure parameters were observed (as in the case of the top surface (A) in specimens manufactured using laser power $P=125 \mathrm{~W}(\mathrm{Sa}=14.7 \mu \mathrm{m}, \mathrm{Sq}=19.1 \mu \mathrm{m})$. In case of the analysed surface, the values of the deepest valleys $\mathrm{Sv}$ in function of varying laser power $\mathrm{P}$ are contained in a range between 9.5 and $95 \mu \mathrm{m}$ (Fig. 7c).

According Krolczyk et al. [30] the Ssk parameter indicates the predominance of peaks on the surface for Ssk $>0$ or valley for $\mathrm{Ssk}<0$. Sku parameter demonstrates presence on the surface inordinately high peaks or deep valleys for Sku $>3$ or their absence on the surface for Sku $<3$.

It is worth noting that the analysed parameters of the top surface (A) geometrical structure are much higher than those recorded for the side surface (B). From the perspective of geometry, the shape of the profile can be described, inter alia, using kurtosis (Sku) and skewness (Ssk) parameters. These two parameters were also studied for the purposes of the paper. The measure of the height distribution curve thinness is the so-called excess, also referred to as kurtosis or coefficient of kurtosis (Sku). For 
(a)

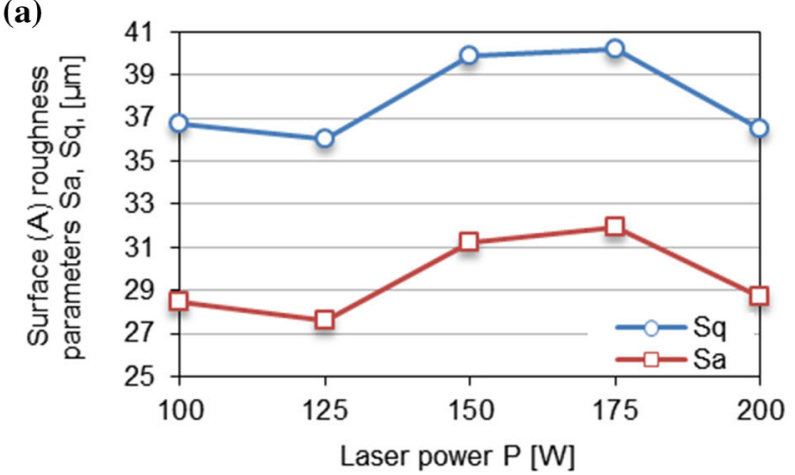

(b)

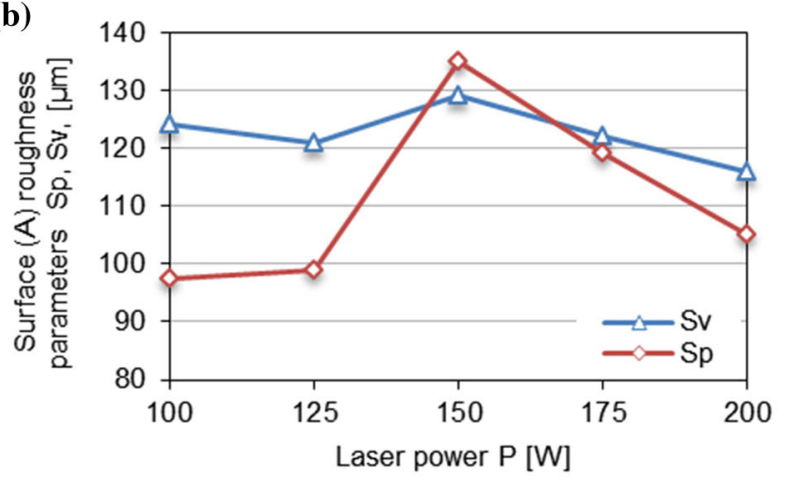

(c)

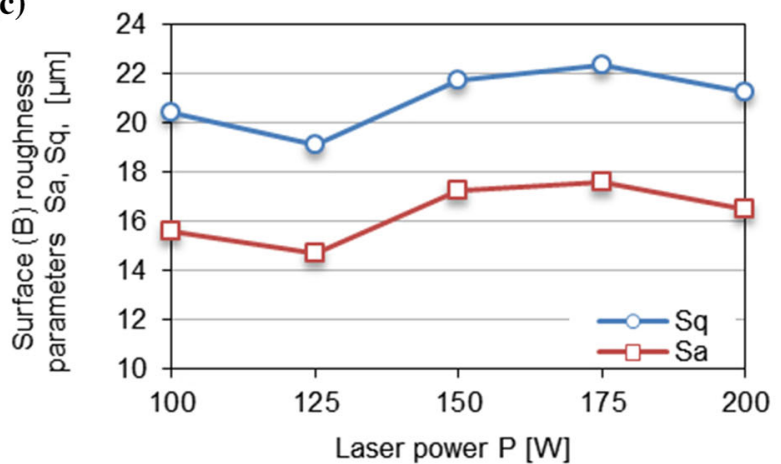

(d)

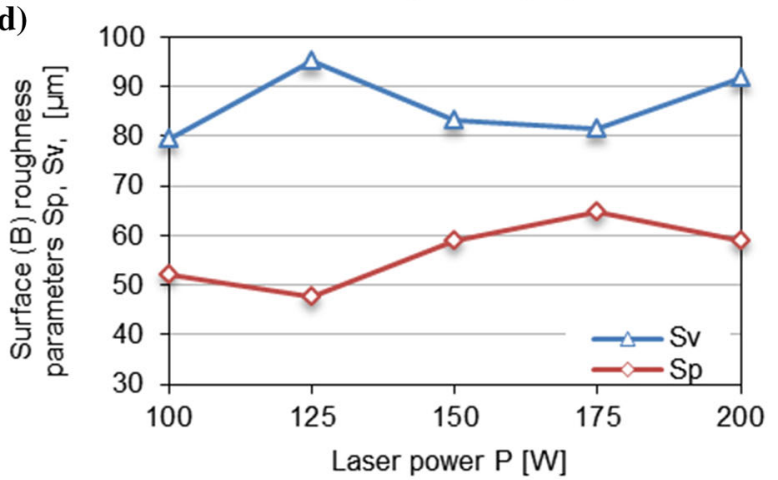

Fig. 7 The changes of spatial parameters of the side surface (B) in the variable laser power function: a average height (Sa) and root-meansquare height $(\mathrm{Sq})$, b maximum peak height (Sp) and maximum valley depth $(\mathrm{Sv})$

the normal height distribution in the profile, the value of kurtosis Sk equals 3. Analysis of the results shown in Fig. 8 reveals that kurtosis Sku for each case is higher than 3 (a)

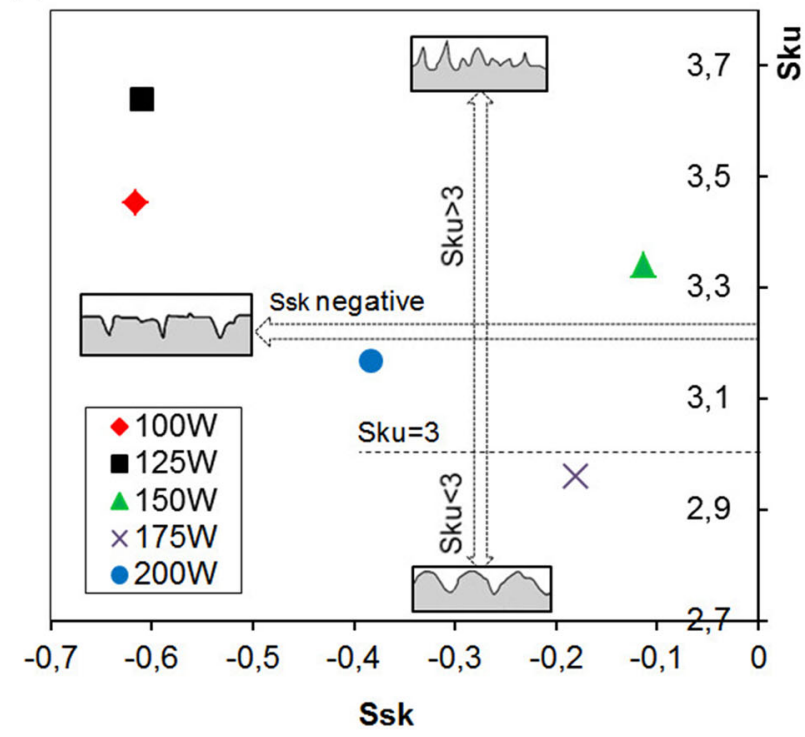

(b)

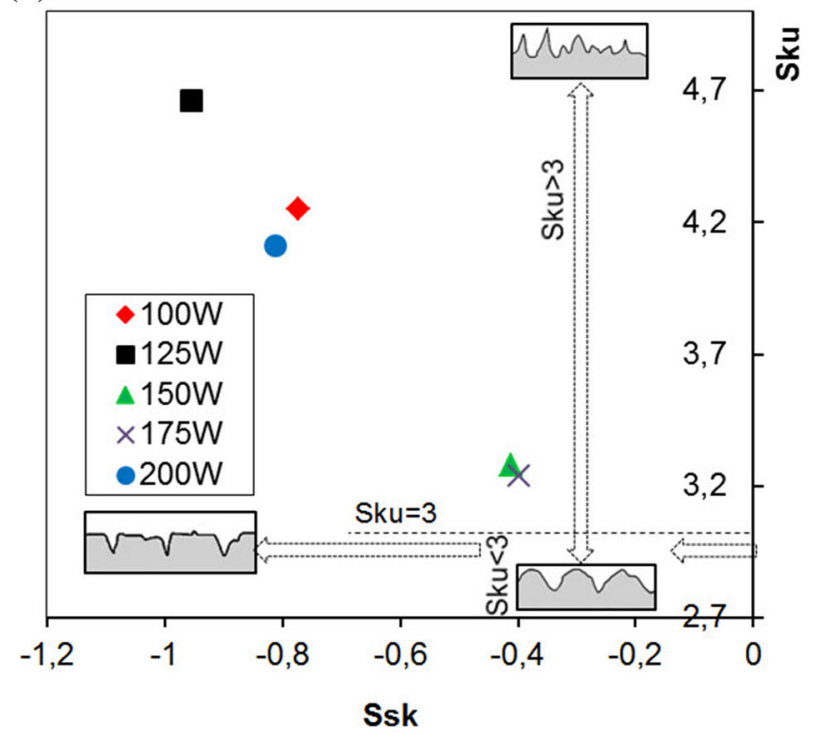

Fig. 8 Map of kurtosis (Sku) and skewness (Ssk) of the distribution for the given laser power values $\mathbf{a}$ on the top surface (A) and $\mathbf{b}$ on the side surface $(\mathrm{B})$

(apart from surface A, beam power $175 \mathrm{~W}$ ). This proves that the roughness profile height distribution curve is thinner, i.e. narrower and taller. The asymmetry of the profile, in turn, is measured by skewness (Ssk). Skewness describes the asymmetry of roughness-height distribution curve with respect to its mean value. The negative value of skewness indicates a surface with plateau-shaped hills, and positive value-sharp-peaked surface, as shown in Fig. 8.

As shown in Fig. 8, in both top (A) and side (B) surfaces, the skewness values were exclusively negative and kurtosis-positive. The peaks are thus thin and sharp (Sku>3), with valleys prevailing in the surface structure $(\mathrm{Ssk}<0)$. The top surface (A) is characterised by higher skewness 
(a)

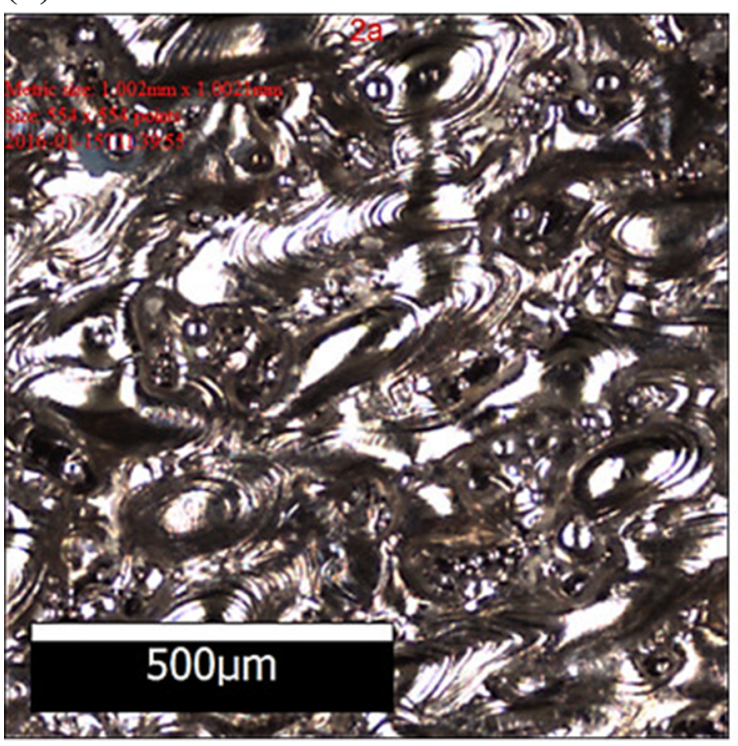

(b)

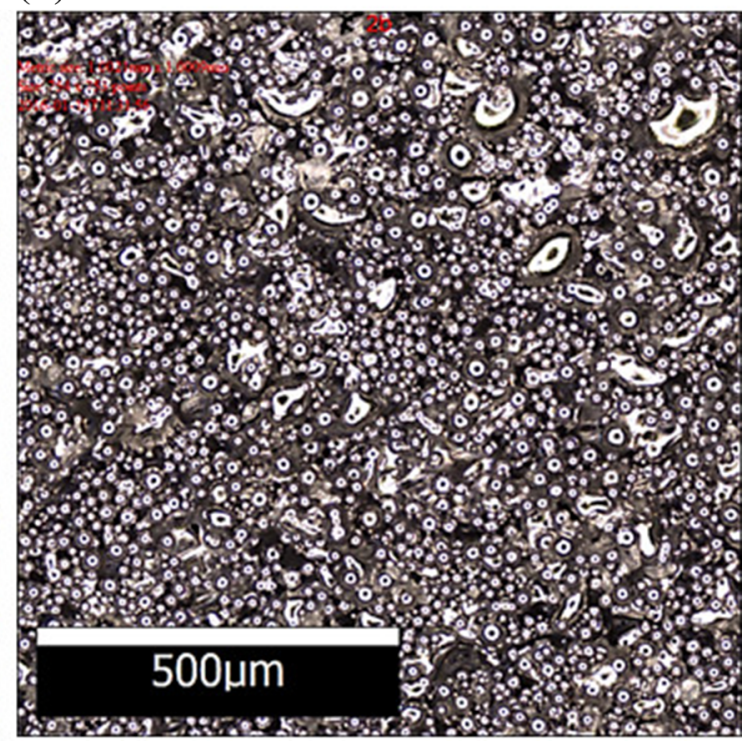

Fig. 9 Comparison of the structure of the top surface (A) and the side surface (B)

values (Ssk) for each laser power. The highest kurtosis value for both surfaces was recorded in specimen manufactured with laser power of $125 \mathrm{~W}$, and the lowest for laser power of $175 \mathrm{~W}$. The highest skewness was recorded for laser power $150 \mathrm{~W}$. The lowest value of this parameter was revealed with laser power $100 \mathrm{~W}$ for the top surface (A), and with laser power $125 \mathrm{~W}$ for the side surface (B). The parameter's values remain within the following ranges: Sku $\rightarrow(2.96 /$ $3.64)$, Ssk $\rightarrow(-0.615 /-0.113)$ for top surface (A); and the following: Sku $\rightarrow$ (3.24/4.66), Ssk $\rightarrow(-0.95 /-0.39)$ for side surface (B). The influence of varying laser power on the values of the parameters can be also observed.

Microscopic images of the tested specimen's surface clearly indicate the influence of the position of the parts axis on the structural characteristics of the surface. According to many papers [31-42], the surface structure after laser melting is specific and different than the structure after machining processes [31-36, 39], hydroabrasive [40, 42] and laser machining [37]. Figure 9 shows an example of microscopic images of the top surface A and side surface B of the parts manufactured using laser power $P=175 \mathrm{~W}$.

Figure 9 clearly indicates the varied structure of the top surface A compared to side surface B. First and foremost, Fig. 9 confirms the significant difference in concentration of peaks of surface unevenness.

\section{Conclusion}

Research presented in the paper revealed the existence of the relation between the laser power $P$ and the stereometric properties of surface in the parts manufactured in SLM processes. The changes of characteristics of the $\mathrm{Sa}$ and $\mathrm{Sq}$ parameters in the laser power $P$ function are non-linear (Fig. 7). However, for some values of laser power $P$ (150, $175 \mathrm{~W}$ ), the Sa and Sq parameters are considerably higher than in case of the remaining laser power values. The topographic properties also differ depending on the location of the surface. The results obtained indicate that the quality of top surfaces of the specimens manufactured is worse as far as the $\mathrm{Sq}$ and $\mathrm{Sq}$ parameters. The top surface (A) demonstrates values higher by as much as over $10 \mu \mathrm{m}$ compared to the side surface (B). The change of the laser power can also have a strong influence on the structure of individual surfaces, as evidenced by the fact that the highest values of the Sa and Sq parameters were achieved at different laser powers (175 W for the top surface and $150 \mathrm{~W}$ for the side surface).

Despite that, they differ in surface structure, which is evidenced by the different values of kurtosis and skewness in both cases (Fig. 8a). The difference in values of these parameters confirms the impact of laser power on the morphological properties of the surface. Moreover, the values of the Sku and Ssk parameters, higher on the side surface (B) than on the top surface (A), confirm the importance of the laser beam axis position versus a given surface during the SLM process.

The analysis of surface morphology in manufactured elements using laser melting allows establishing the optimum finish processes to be performed on the parts. The study also revealed that surface structure analysis should not only be focused solely on basic parameters such as average height $(\mathrm{Sa})$ or root-mean-square height $(\mathrm{Sq})$, but also on parameters such as kurtosis (Sku) and skewness 
(Ssk), which yield important information on surface stereometry. Precisely, identification of surface parameters ( $\mathrm{Sa}, \mathrm{Sq}, \mathrm{Sp}, \mathrm{Sv}$ and $\mathrm{Sku}, \mathrm{Ssk}$ ) allows optimisation of friction conditions during exploitation. Also, it allows for assessing the properties of parts, for example, the ability to integrate medical implants with live organism tissue.

Open Access This article is distributed under the terms of the Creative Commons Attribution 4.0 International License (http://creative commons.org/licenses/by/4.0/), which permits unrestricted use, distribution, and reproduction in any medium, provided you give appropriate credit to the original author(s) and the source, provide a link to the Creative Commons license, and indicate if changes were made.

\section{References}

1. Santos EC, Shiomi M, Osakada K, Laoui T (2006) Rapid manufacturing of metal components by laser forming. Int $\mathrm{J}$ Mach Tools Manuf 46(12-13):1459-1468

2. Budzik G, Burek J, Bazan A, Turek P (2016) Analysis of the accuracy of reconstructed two teeth models manufactured using the 3DP and FDM technologies. Strojniski vestnik J Mech Eng 62(1):11-20

3. Wilkes J, Hagedorn Y-Ch, Meiners W, Wissenbach K (2013) Additive manufacturing of $\mathrm{ZrO}_{2}-\mathrm{Al}_{2} \mathrm{O}_{3}$ ceramic components by selective laser melting. Rapid Prototyp J 19(1):51-57

4. Yadroitsev I, Gusarov A, Yadroitsava I, Smurov I (2010) Single track formation in selective laser melting of metal powders. J Mater Process Technol 210(12):1624-1631

5. Tolosa I, Garciandia F, Zubiri F, Zapirain F, Esnaola A (2010) Study of mechanical properties of AISI 316 stainless steel processed by "selective laser melting", following different manufacturing strategies. Int J Adv Manuf Technol 51:639-647

6. Amato KN, Gaytan SM, Murr LE, Martinez E et al (2012) Microstructures and mechanical behavior of Inconel 718 fabricated by selective laser melting. Acta Mater 60(5):2229-2239

7. Jia Q, Gu D (2014) Selective laser melting additive manufacturing of Inconel 718 superalloy parts: densification, microstructure and properties. J Alloy Compd 585(5):713-721

8. Takaichi A, Suyalatu Nakamoto T, Joko N et al (2013) Microstructures and mechanical properties of Co-29Cr-6Mo alloy fabricated by selective laser melting process for dental applications. J Mech Behav Biomed Mater 21:67-76

9. Louvis E, Fox P, Sutcliffe ChJ (2011) Selective laser melting of aluminum components. J Mater Process Technol 211(2):275-284

10. Olakanmi EO (2013) Selective laser sintering/melting (SLS/ SLM) of pure $\mathrm{Al}, \mathrm{Al}-\mathrm{Mg}$, and Al-Si powders: effect of processing conditions and powder properties. J Mater Process Technol 213:1387-1405

11. Gu D, Hagedorn Y-Ch, Meiners W, Meng G et al (2012) Densification behavior, microstructure evolution, and wear performance of selective laser melting processed commercially pure titanium. Acta Mater 60:3849-3860

12. Koike M, Greer P, Owen K, Lilly G et al (2011) Evaluation of titanium alloys fabricated using rapid prototyping technologieselectron beam melting and laser beam melting. Materials 4:1776-1792

13. Campbell I, Bourell D, Gibson I (2012) Additive manufacturing: rapid prototyping comes of age. Rapid Prototyp J 19(4):255-258

14. Hao L, Dadbakhsh S, Seaman O, Felstead M (2009) Selective Laser melting of a stainless steel and hydroxyapatite composite for load- bearing implant development. J Mater Process Technol 209:5793-5801

15. Lyons B (2012) Additive manufacturing in aerospace: examples and research outlook. Bridge 42(1):13-19

16. Vandenbroucke B, Kruth J-P (2007) Selective laser melting of biocompatible metals for rapid manufacturing of medical parts. Rapid Prototyp J 13(4):196-203

17. Pyka G, Kerckhofs G, Papantoniou I, Speirs M et al (2013) Surface roughness and morphology customization of additive manufactured open porous Ti6Al4V structures. Materials 6:4737-4757

18. Dohan Ehrenfest D, Coelho PG, Kang B-S, Sul Y-T et al (2010) Classification of osseointegrated implant surfaces: materials, chemistry and topography. Trends Biotechnol 28(4):198-206

19. Le Guehennec L, Soueidan A, Layrolle P, Amouriq Y (2007) Surface treatments of titanium dental implants for rapid osseointegration. Dent Mater 23:844-854

20. Spierings AB, Herres N, Levy G (2011) Influence of the particle size distribution on surface quality and mechanical properties in AM steel parts. Rapid Prototyp J 17(3):195-202

21. Yadroitsev I, Smurov I (2011) Surface morphology in selective laser melting of metal powders. Phys Proc 12:264-270

22. Yasa E, Kruth J-P (2011) Application of laser re-melting on selective laser melting parts. Adv Prod Eng Manag 6(4):259-270

23. Strano G, Hao L, Everson RM, Evans KE (2013) Surface roughness analysis modelling and prediction in selective laser melting. J Mater Process Technol 213:589-597

24. Yasa E, Kruth J-P (2011) Microstructural Investigation of selective laser melting 316L stainless steel parts exposed to laser re-melting. Phys Proc 12:264-270

25. Sato Y, Tsukamoto M, Yamashita Y (2015) Surface morphology of Ti-6Al-4V plate fabricated by vacuum selective laser melting. Appl Phys B Lasers Opt 119:545-549

26. Yadroitsava I, Els J, Booysen G, Yadroitsev I (2015) Peculiarities of single track formation from Ti-6Al-4V alloy at different laser power densities by selective laser melting. S Afr J Ind Eng 26(3):86-95

27. Song B, Dong Sh, Zhang B, Lia H, Coddet Ch (2012) Effects of processing parameters on microstructure and mechanical property selective laser melted Ti6Al4V. Mater Des 35:120-125

28. Li R, Liu J, Shi U, Wang L, Jiang W (2012) Balling behavior of stainless steel and nickel powder during selective laser melting process. Int J Adv Manuf Technol 59:1025-1035

29. Zhou X, Liu X, Zhang D, Shen Z, Liu W (2015) Balling phenomena in selective laser melted tungsten. J Mater Process Technol 222:3342

30. Krolczyk GM, Krolczyk JB, Maruda RW, Legutko S, Tomaszewski M (2016) Metrological changes in surface morphology of high-strength steels in manufacturing processes. Measurement 88:176-185

31. Józwik J, Mika D (2015) Diagnostics of workpiece surface condition based on cutting tool vibrations during machining. Adv Sci Technol Res J 9:57-65

32. Pytka J, Tarkowski P, Budzyński P, Józwik J (2017) Method for testing and evaluating grassy runway surface. J Aircr 54:229-234

33. Novák M, Náprstková N, Józwik J (2015) Analysis of the surface profile and its material share during the grinding Inconel 718 alloy. Adv Sci Technol Res J 9:41-48

34. Niemczewska-Wojcik M (2017) Multi-sensor measurements of titanium alloy surface texture formed at subsequent operations of precision machining process. Measurement 96:8-17

35. Merola M, Ruggiero A, De Mattia JS, Affatato S (2016) On the tribological behavior of retrieved hip femoral heads affected by metallic debris. A comparative investigation by stylus and optical profilometer for a new roughness measurement protocol. Measurement 90:365-371 
36. Dziedzic K, Zubrzycka-Wróbel J, Józwik J, Barszcz M, Siwak P, Chałas R (2016) Research on tribological properties of dental composite materials. Adv Sci Technol Res J 10:144-149

37. MacAulay GD, Senin N, Giusca CL, Leach RK (2016) Study of manufacturing and measurement reproducibility on a laser textured structured surface. Measurement 94:942-948

38. Krolczyk JB (2016) Metrological changes in the surface morphology of cereal grains in the mixing process. Int Agrophys 30:193-202

39. Wojciechowski S, Twardowski P, Wieczorowski M (2014) Surface texture analysis after ball end milling with various surface inclination of hardened steel. Metrol Meas Syst 21:145-156
40. Kumar R, Chattopadhyaya S, Dixit AR, Bora B, Zelenak M, Foldyna J et al (2017) Surface integrity analysis of abrasive water jet-cut surfaces of friction stir welded joints. Int J Adv Manuf Technol 88:1687-1701

41. Srivastava M, Tripathi R, Hloch S, Chattopadhyaya S, Dixit AR (2016) Potential of using water jet peening as a surface treatment process for welded joints. Proc Eng 149(2016):472-480

42. Hloch S, Ruggiero A (2013) Online monitoring and analysis of hydroabrasive cutting by vibration. SAGE Publications, London, p 10 